Geerst, I.M.M. van der, Heuvel-Eibrink, M.M. van den, Vliet, L.M. van, Pluijm, S.M.F., Streng, I.C., Michiels, E.M.C., Pieters, R., Darlington A.S.E. Talking about death with children with incurable

\begin{tabular}{|l|l|}
\hline $\begin{array}{l}\text { Postprint } \\
\text { Version }\end{array}$ & 1.0 \\
\hline Journal website & http://linkinghub.elsevier.com/retrieve/pii/S0022-3476(15)00999-3 \\
\hline Pubmed link & http://www.ncbi.nlm.nih.gov/pubmed/26427964 \\
\hline DOI & $10.1016 / j . j p e d s .2015 .08 .066$ \\
\hline
\end{tabular}

This is a NIVEL certified Post Print, more info at http://www.nivel.eu

\title{
Talking about Death with Children with Incurable Cancer: Perspectives from Parents
}

IVANA M. M. VAN DER GEEST, MD ${ }^{1}, 2$, MARRY M. VAN DEN HEUVEL-EIBRINK, MD, PHD ${ }^{1}$, LiEsBeth M. VAN VLIET, PHD ${ }^{3}$, SASKia M. F. PluiJM, PHD ${ }^{2}$, ISABELle C. STRENG, MSC ${ }^{2}$, ERnA M. C. MiChIELS, MD, PHD ${ }^{2}$, RoB PIETERS, MD, HHD $^{1}$, AND ANNE-SOPHIE E. DARLINGTON, PHD

Objective To investigate the rationale and consequences associated with a parent's decision to discuss death with a child with incurable cancer.

Study design We present data from a larger retrospective study involving bereaved parents of a child who died of cancer. Parents were asked whether they had discussed the impending death with their child, whether they reflected on this discussion positively, their reasons for not discussing death with their child, and the manner in which the conversation regarding death occurred. The data were analyzed qualitatively using a framework approach.

Results Of the 86 parents of 56 children who answered the questions regarding discussing death with their child, 55 parents of 35 children did not discuss the impending death with their child. The following themes were identified: the parents' inability to discuss the impending death; the parents' desire to protect their child; views regarding talking with children; parents' views of child characteristics; the child's unwillingness to discuss the subject; lack of opportunity to talk; and the child's disability. The parents who did discuss death with their child generally used symbolic and/or religious narratives, or they had brief, direct conversations regarding death. The majority of parents felt positive regarding their decision about whether to talk with their child about his/her impending death.

Conclusion Most parents in this study cited several reasons for not discussing death with their child. Our findings highlight the sensitive and complex issues surrounding these conversations, indicating that there may be a role for clinicians in supporting parents. (J Pediatr 2015;167:1320-6). 
Geerst, I.M.M. van der, Heuvel-Eibrink, M.M. van den, Vliet, L.M. van, Pluijm, S.M.F., Streng, I.C., Michiels, E.M.C., Pieters, R., Darlington A.S.E. Talking about death with children with incurable cancer: perspectives from parents. Journal of Pediatrics: 2015, 167(6), 1320-1326

In recent decades, the importance of open, honest communication in the field of pediatric palliative care has been underscored by several studies and recommendations. ${ }^{1-11}$ In pediatrics, communication is often a 3-way process involving the healthcare professionals, the parents, and the child. ${ }^{12}$ Here, we explored the topic of communicating about death between parents and their child who had incurable cancer.

Strikingly, a landmark study of 429 Swedish parents with terminally ill children found that only $34 \%$ of parents talked about death with their terminally ill child. ${ }^{13}$ The finding that a relatively large percentage of parents did not talk with their terminally ill child about death raises important questions regarding why some parents may choose not to talk with their child about the child's impending death. In a qualitative study of 25 parents of 17 children who died because of brain cancer, Zelcer et al found that parents did not discuss the impending death with their child because they were "in denial" regarding their child's prognosis ${ }^{14}$; moreover, the parents did not wish to jeopardize their own hopes - or their child's hopes-for a cure. ${ }^{14}$ Beale et a $1{ }^{15}$ referred to "myths" regarding withholding communication about end-of-life issues, including the perceived myths that discussing death will induce depression in the child and that children lack the capacity to adequately understand death.

Parents who discuss death with their terminally ill child are confronted with the issue of how to talk about death. To address this issue, several recommendations and guidelines have been published with the aim of supporting parents and healthcare professionals during this process. ${ }^{15,16}$ One such approach is the "6 Es" (Establish, Engage, Explore, Explain, Empathize, and Encourage), which was established to help parents communicate with their terminally ill child. ${ }^{15}$ However, research regarding these recommendations are limited.

Another key issue is the long-term consequences of a parent's decision regarding whether to discuss death with their terminally ill child. For example, Kreicbergs et al previously reported that none of the parents who discussed death with their child regretted the conversation after the loss of the child. ${ }^{13}$ On the other hand, more than $25 \%$ of parents who did not discuss death with their child ultimately regretted that decision. ${ }^{13}$ Given this background information, the goal of the current study was to determine: (1) the percentage of parents in our cohort who discussed death with their child with incurable cancer; (2) the parents' reasons for not discussing death with their child; (3) how parents discussed the topic of death with their child; and (4) how parents retrospectively viewed their decision to either discuss or not discuss death with their child. 
Geerst, I.M.M. van der, Heuvel-Eibrink, M.M. van den, Vliet, L.M. van, Pluijm, S.M.F., Streng, I.C., Michiels, E.M.C., Pieters, R., Darlington A.S.E. Talking about death with children with incurable cancer: perspectives from parents. Journal of Pediatrics: 2015, 167(6), 1320-1326

\section{METHODS}

All parents who lost a child to cancer from 2000 through 2004 either during or after receiving treatment at the Erasmus Medical Center-Sophia Children's Hospital, Department of Pediatric Oncology/Hematology were invited to complete a questionnaire that was part of a larger study focusing on parents' experiences regarding pediatric palliative care. ${ }^{17}$ In total, the parents of 123 of the 135 children who died from 2000 through 2004 were eligible for this study. The parents of 12 children were not approached for this study for the following reasons. In 5 cases, the physician believed it would place too heavy a burden on the parents; 2 of the children died while being diagnosed with cancer; 2 children died because of sudden toxicity during treatment; 2 children were prematurely born infants who had multiple organ problems and died shortly after birth; and 1 family was seeking asylum in The Netherlands. ${ }^{17}$ This study focused on the questions that parents completed with respect to discussing death with their child. Specifically, the parents were asked whether they discussed the impending death with their child and whether-in retrospect - they reflect positively on this decision.

Parents who reported that they did not talk with their child about death were additionally asked in an open ended question their reason(s) for not doing so. Parents who reported that they talked with their child about death were additionally asked in an open-ended question to specify how they talked to their child about death. The parents were also given the opportunity to provide additional comments regarding their experiences with respect to discussing or not discussing the impending death. This study was approved by the Medical Ethics Committee of the Erasmus Medical Center, Rotterdam, the Netherlands (MEC number 2007-362). Parents received an invitation letter, an information sheet describing the aims of the study, the questionnaire (including instructions), and an informed consent form. Parents who wished to receive more information were invited to contact the research physician and/or psychologist. If desired, a pediatric oncologist and psychologist were available to provide the parents with emotional support.

\section{Data Analyses}

Descriptive analyses were performed using SPSS ver. 21.0 (IBM Corp, Armonk, New York). Talking about death was defined as either one or both parents discussing the topic of death with their child. Differences between fathers and mothers with respect to discussing death with the child were analyzed using the $\mathrm{C}_{2}$ test. To analyze the findings from the open-ended questions, qualitative analyses were performed using a framework approach in order to identify any emerging themes. ${ }^{18}$ This approach consisted of the following stages: (1) becoming familiar with the data; (2) coding the data; (3) developing a working analytical framework; (4) applying the analytical framework; (5) charting the data into the framework matrix; and (6) interpreting the data. ${ }^{19}$ In our study, the parents' quotations were coded by one author (I.v.d.G.), and a quality control of $10 \%$ of the quotes (selected at random) was performed by another author (A.-S.D.). Any discrepancies with respect to coding were discussed with a third author (M.v.d.H.) in order to reach consensus. 
Geerst, I.M.M. van der, Heuvel-Eibrink, M.M. van den, Vliet, L.M. van, Pluijm, S.M.F., Streng, I.C., Michiels, E.M.C., Pieters, R., Darlington A.S.E. Talking about death with children with incurable cancer: perspectives from parents. Journal of Pediatrics: 2015, 167(6), 1320-1326

\section{RESULTS}

Of the 246 parents of 123 children who were sent a questionnaire, 89 parents of 57 deceased children returned the questionnaire. Among the questionnaires that were returned, 86 parents (54 mothers [63\%] and 32 fathers [37\%]) of 56 children completed the question related to discussing death with their terminally ill child. The median interval between the child's death and completion of the questionnaire was 5 years (range: 3-8 years). A detailed description of the cohort is presented in the Table and has been reported previously. ${ }^{17}$

\section{Talking about Death}

Fifty-five of the 86 parents who responded (64\%) did not discuss the impending death with their child; the median age of these 35 children at the time of their death was 7 years (range: $1-17$ years). The other 31 parents $(36 \%)$ discussed the impending death with their child; the median age of these 21 children at the time of death was 8 years (range: $3-15$ years). No significant difference was found between the number of fathers and mothers who discussed death $\left(\mathrm{N}=14\right.$ and 17 , respectively; $\mathrm{C}_{2}$ value $=$ $1.3 ; \mathrm{P}=.25)$.

\section{Parents' Reasons for Not Discussing Death withTheir Child}

Fifty-three of the 55 parents provided an explanation for why they did not talk with their child about death; the majority of these parents stated several reasons. The following themes were identified: the parents' inability to discuss the impending death; the parents' desire to protect their child; views regarding talking with children; parents' views of child characteristics; the child's unwillingness to discuss the subject; lack of opportunity to talk; and the child's disability (Figure 1). These themes are discussed in detail below.

\section{[TABLE]}

\section{Parents' Inability to Discuss the Subject of Death with the Child}

Some of the parents reported that they struggled with the subject and/or did not have confidence in their ability to convey the message that their child had a terminal illness. Other parents felt unable to cope with their child's approaching death or remained hopeful for a cure. Oftentimes, by the time they wanted to discuss death with the child, it was too late. In addition, 1 parent explicitly stated that fear was the underlying reason for not discussing death with the child. This parent described a sense of fear regarding the child's response ("Would he become angry, or very sad?"), but also expressed fear that the child would no longer be able to enjoy his final days.

\section{Parents' Desire to Protect Their Child}

Several parents indicated that they did not wish to cause their child additional pain or anguish. As one parent wrote, "Our child felt good. He had no pain or awareness of the situation. I wanted him to enjoy life, and I gave him pain medication as needed." Other parents reported that they did not want to extinguish their child's hopes for a cure. 
Geerst, I.M.M. van der, Heuvel-Eibrink, M.M. van den, Vliet, L.M. van, Pluijm, S.M.F., Streng, I.C., Michiels, E.M.C., Pieters, R., Darlington A.S.E. Talking about death with children with incurable cancer: perspectives from parents. Journal of Pediatrics: 2015, 167(6), 1320-1326

\section{Views about Talking to a Child}

A few of the parents reported their views regarding talking to children about death. For example, some parents felt that it is inappropriate to tell a child that he or she will die, and they felt that the doctor should also refrain from telling the child. Occasionally, parents were discouraged from talking to their child about death. One such parent specifically noted that a healthcare professional discouraged him/her from discussing death with the child, whereas another parent did not state explicitly who discouraged him/her.

\section{Parents' Views of Child Characteristics}

Several parents stressed that their child's personality was a reason for not discussing the child's impending death. For example, 1 parent indicated that his/her child "was not a child who could talk about death," and some parents described their child as being too timid. Several parents felt that their child was too young for this type of discussion, but they also often acknowledged that they believed that their child was aware of what was happening. Some parents interpreted their child's deteriorating condition, sudden change in behavior, or appearance of being "at peace" after their healthcare professional was unable to provide a cure as a signal that their child was aware of his/her impending death. Some parents used what they believed was their child's perceived awareness as a reason for not talking; as 1 parent stated, "We both knew what was happening, so we didn't need to talk about it."

\section{[FIGURE 1]}

\section{The Child's Unwillingness to Discuss the Subject of Death}

A number of parents reported that their child clearly indicated that he/she did not want to discuss the subject of death. One parent's child had made it clear that he/she preferred to discuss other topics such as positive things in life. Other parents' children actively avoided any discussions related to death, for example by refusing to answer sensitive questions. Lastly, some parents did not discuss the subject of death with their child because their child never initiated such a conversation, which could reflect unwillingness on the part the child.

\section{Lack of Opportunity to Talk about Death}

Some parents did not talk with their child about death because the child's death was sudden, the child was young, or there were physical restrictions (eg, the child was in a coma, was mechanically ventilated, or was otherwise unable to communicate).

\section{The Child's Disability}

Some parents cited their child's disability as a reason to not discuss death with the child. However, it was not always clear whether they were referring to a physical or mental disability. 
Geerst, I.M.M. van der, Heuvel-Eibrink, M.M. van den, Vliet, L.M. van, Pluijm, S.M.F., Streng, I.C., Michiels, E.M.C., Pieters, R., Darlington A.S.E. Talking about death with children with incurable cancer: perspectives from parents. Journal of Pediatrics: 2015, 167(6), 1320-1326

\section{Parents Who Discussed Their Child's Death with the Child}

Thirty-one parents of 21 children talked with their child about death. Several of these parents used a symbolic story to talk with their child. Some parents spoke about death in a way that they believed would make sense to their child; for example, 1 parent told their child — who adored flying - that one day he would fly away and never return. Other parents used narratives written specifically to help parents talk with their child; one such example is the book Naar het Regenboogbos (To the Rainbow Forest) by Susanna-Elly Marijs, which is about a country where children can go to after death, where sickness and pain do not exist, and where children can play in a forest. ${ }^{20}$ One parent who used this story hoped that telling this story to his/her child might help make the concept of death more tangible to the child and would help alleviate the child's fear of dying. Another story that some parents used was designed by a spiritual caregiver in our hospital and is about a beetle that lived at the bottom of a reservoir, swam to the surface, and was transformed into a dragonfly. One parent who used this story stated, "My child wanted to hear this story many times. At the end of the story, he would always start to cry, and I felt that he really understood the message." Some parents found religious stories helpful. One parent stated, "We told him/her that God has meaning in everything, and that somehow we would always be connected." Another parent wrote, "Our child was proud that she would get to play in God's garden." Several parents described having a brief conversation with their child about the child's impending death. Some of these parents used a very direct approach, telling their child he/she could not be cured or asking the child whether he/she thought that he/ she could be cured. Other parents talked with their child when the child requested information regarding his/her prognosis.

\section{Parents' Feelings Regarding Either Discussing OR Not Discussing Death WITH THEIR CHILD}

The majority of parents reflected positively on their decision either to discuss or not discuss death with their child. Figure 2 summarizes the relative number of parents who replied "yes," "no," or "I don't know" when asked whether they reflected positively on their decision. Eight of the parents who did not discuss death did not answer this question, and 1 parent who did discuss death did not answer this question. Figure 2 also provides example responses written by the parents for each choice. Twenty-nine of the responding 47 parents who did not talk with their child about the impending death reflected positively on their decision (ie, answered "yes"). Some of these 29 parents indicated that their child clearly did not want to talk about death or avoided the conversation. A few of the parents who did not reflect positively on their decision not to talk indicated that there was no possibility to discuss death or that they chose not to discuss it because they still hoped for a cure.

More than three-quarters of the parents who discussed death with their child felt positive about having had the conversation. These parents reported the following benefits of having a conversation with their child regarding death: the parents could help eliminate the child's fear; the child was able to help organize the funeral themselves according to his/her own wishes; and the open and honest nature of the conversation brought some families closer together. In a few cases, the parents who talked about death with their child reported that this experience was not positive, and this was often based on the child's resulting emotional response (figure 2). 
Geerst, I.M.M. van der, Heuvel-Eibrink, M.M. van den, Vliet, L.M. van, Pluijm, S.M.F., Streng, I.C., Michiels, E.M.C., Pieters, R., Darlington A.S.E. Talking about death with children with incurable cancer: perspectives from parents. Journal of Pediatrics: 2015, 167(6), 1320-1326

\section{[FIGURE 2]}

\section{DISCUSSION}

Here, we report that approximately two-thirds of parents in our Dutch cohort chose not to talk with their terminally ill child regarding the child's impending death. This finding is consistent with a previous study by Kreicbergs et al. ${ }^{13}$ Several reasons were cited by parents for not discussing death with their child. Some parents reported fear in [Figure 2] association with talking about death, some felt unable to cope with their child's impending death, and some did not feel confident talking with their child about death. A previous report showed that some parents reported feeling guilty or experienced their child's approaching death as a "failure to protect (their) child". ${ }^{0}$ Such parental insecurities can further complicate communication and openness between the parent and child.

Many parents described a desire to protect their child from bad news, a finding consistent with previous reports. ${ }^{10,12,21-24}$ A parent's desire to protect the child is a common theme, in palliative care settings as well as shortly after receiving a diagnosis of childhood cancer ${ }^{25}$ or other potentially life-threatening chronic illness. ${ }^{26}$ On the other hand, the reasons a parent might choose to not discuss death with his/her child can include having a child who is unwilling to talk about death or a child who does not initiate a conversation regarding death. Data suggest that this situation can lead to a phenomenon known as "mutual pretense," in which both the parent and child are aware of the impending death, but neither is willing or able to discuss it. ${ }^{10}$ Mutual pretense can cause feelings of isolation in the child, and this can also lead to a decreased level of trust by the child in his/her parents and healthcare providers. ${ }^{1,6,10,11,14,21,24,27-29}$ Another theme was related to views regarding talking with children about death. Previous publications discussed several potential "myths" related to withholding open communication regarding the child's impending death during the palliative phase. One such myth is that children under the age of 10 years are not aware of their imminent death (and therefore will not experience anxiety or concerns); another myth is that discussing death with the child can lead to severe depression in the child. ${ }^{9,15}$ Consistent with these notions, our results show that the parents' views often prevent them from discussing death with their child. Another theme involved the parents' views of child characteristics. For example, several parents mentioned their child's young age as a reason to not discuss death with the child, even though the children were often aware of their prognosis.

Developmentally speaking, young children may not be able to understand fully the implications of dying; however, as previous studies suggest, terminally ill children of all ages can be aware of their impending death. ${ }^{1,10,16,23,25,30,31}$ This awareness can arise from changes in circumstances or in the behavior of the parents and/or healthcare professionals. Children can often identify and correctly interpret these changes (for example, when the child is suddenly excluded from the conversations with health care professionals). In addition, contact with other children with

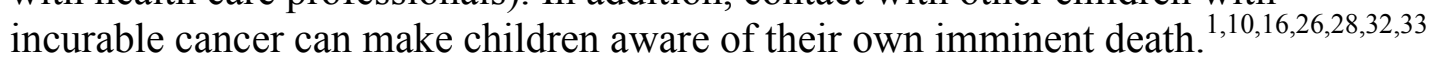
According to the parents in our study, some of the children clearly stated that they did not want to talk about death, whereas other children avoided the conversation, for example by not answering delicate questions from their parents. The published 
Geerst, I.M.M. van der, Heuvel-Eibrink, M.M. van den, Vliet, L.M. van, Pluijm, S.M.F., Streng, I.C., Michiels, E.M.C., Pieters, R., Darlington A.S.E. Talking about death with children with incurable cancer: perspectives from parents. Journal of Pediatrics: 2015, 167(6), 1320-1326

literature gives less attention to the possibility that children may not want to talk with their parents about their impending death. In fact, both studies and recommendations underscore the importance of open, honest communication, ${ }^{1-11}$ and discussions are increasingly focused on how we should talk with children about death. Based on the results of our study and the work of other groups, not discussing the subject of death with their parents may be the best option for some children. ${ }^{2,32-34}$ Moreover, although some children may not want to talk about death with adults, they may want to discuss this topic with their peers. ${ }^{10}$ Several of the parents in our study reported that they lacked the opportunity to discuss death with their child, and some of these parents did not reflect positively on the fact that they did not discuss death with their child.

Research by Wolfe et al has revealed that - for some parents - a "gap" can occur between the time at which the oncologist documents the prognosis and the time at which the parents fully understand and accept the prognosis; this gap can be longer than 3 months. ${ }^{35}$ This delay may explain why some parent experienced their child's death as sudden and therefore believed they had no opportunity to talk with their child about death. In addition, in some cases the rapid progression of the illness may have led to a situation in which there was no longer an opportunity to talk with the child about death. Importantly, in these situations, parents are unable to say goodbye and let go, which are essential elements in the grieving process. ${ }^{6,36}$ One-third of the parents in our study talked with their child about death, and many did so using narratives. According to some parents, their children often found comfort in the idea of going to Heaven; this is consistent with previous studies. ${ }^{6}$ The fact that the parents reported using a variety of approaches to discuss death with the child illustrates that there are several effective ways to communicate with a child regarding death. Three-quarters of the parents who discussed death with their child reflected positively on having had this discussion with their child. In some cases, the parents reported that talking about death was a means of minimizing the child's fear. Our results show that discussing the topic of death with the child can create an open atmosphere within the family and can help the family grow closer. Nevertheless, we cannot exclude the possibility that the subgroup of parents who talked with their child about death came from families with an inherently open communication style, leading to a possible bias in the results.

In contrast with a previous study, ${ }^{13}$ we found that some of the parents in our study did not feel positive about their conversation with their child regarding death. Some of the parents in our study reported that these feelings arose primarily because their child had reacted with strong emotions following their conversation regarding the impending death. One such parent stated that she wished she had been better prepared for this. In clinical practice, terminally ill children can respond differently upon learning that their condition is terminal; these responses can range from reacting calmly to becoming angry. ${ }^{6,21}$ Although these responses can appear severe, it is important to remember that such emotional responses by a child are often considered normal behavior and do not necessarily indicate that broaching this subject was inappropriate for these children. Thus, consistent with previous reports, we believe that a parent should not avoid discussing death with the child simply to avoid an emotional response by the terminally ill child, particularly when the child and family have adequate support.

${ }^{15}$ This study has several limitations that warrant discussion. 
Geerst, I.M.M. van der, Heuvel-Eibrink, M.M. van den, Vliet, L.M. van, Pluijm, S.M.F., Streng, I.C., Michiels, E.M.C., Pieters, R., Darlington A.S.E. Talking about death with children with incurable cancer: perspectives from parents. Journal of Pediatrics: 2015, 167(6), 1320-1326

First, the low response rate precludes our ability to generalize our findings. In addition, because the information was obtained by written questionnaire, there was no opportunity to question the parents further regarding their responses in order to obtain more details. Moreover, overlap was observed in some of the categories, although such overlap is generally not uncommon in an analysis of this nature. Lastly, although data were obtained from both parents of some children, this subgroup was relatively small; therefore, we were unable to compare the responses of mother-father dyads.

With respect to clinical practice, our findings suggest that the decision regarding whether - and how - to talk with a child about death should be tailored based on individual context. In the palliative phase of care, most parents base their decision in light of good parenting. This concept, which was described previously by Hinds et al, underscores the notion that parents make decisions that they feel are in the child's best interest. ${ }^{37-40}$ In addition to benefiting the child, this approach also helps parents during the grieving process. ${ }^{38}$ We propose that clinicians can play a central role in: (1) exploring whether parents wish to talk with their child about death; (2) identifying the parents' reason(s) for either discussing or not discussing death with their child; and (3) understanding the factors that may cause the parents to regret their decision over the long term. Parents should be supported with respect to their views regarding discussing death with their child, and this support should be provided in a non-directive manner once the underlying rationale has been explored. For example, clinicians can support parents who feel insecure, or they can explain the possible consequences of "protecting" the child from knowledge regarding the impending death. Open, honest communication is important; however, as our data show, not all parents feel confident discussing impending death with their child. It is therefore equally important to guide and support parents through the process of talking with their child about death while remaining mindful of complex family dynamics. Lastly, our results suggest that parents should be adequately prepared for their child's emotional responses during — and after - any such conversations with the child.

Overall, two-thirds of parents in our study whose child had incurable cancer did not talk with him or her about the impending death, and multiple reasons were cited for this decision. The parents who did talk about death used mostly symbolic or religious narratives, or they had brief, direct conversations with their child regarding death. In retrospect, most of the parents felt positive about their decision, regardless of whether they discussed death with their child or not. Our findings highlight the complexities surrounding these conversations and indicate that clinicians can play a key role in supporting parents.

We thank the mothers of the Dutch Childhood Cancer Parent Organization (Vereniging-Ouders, Kinderen en Kanker), who critically reviewed the questionnaire regarding parents' experiences of care during the pediatric palliative phase. We also thank Curtis Barrett, $\mathrm{PhD}$ (English Editing Solutions) for editing the initial manuscript. 
Geerst, I.M.M. van der, Heuvel-Eibrink, M.M. van den, Vliet, L.M. van, Pluijm, S.M.F., Streng, I.C., Michiels, E.M.C., Pieters, R., Darlington A.S.E. Talking about death with children with incurable cancer: perspectives from parents. Journal of Pediatrics: 2015, 167(6), 1320-1326

\section{REFERENCES}

1. Faulkner KW. Talking about death with a dying child. Am J Nurs 1997; 97:64-9.

2. Whittam EH. Terminal care of the dying child. Psychosocial implications of care. Cancer 1993;71:3450-62.

3. American Academy of Pediatrics Committee on Hospital Care: child life programs. Pediatrics 1993;91:671-3.

4. Masera G, Spinetta JJ, Jankovic M, Ablin AR, D'Angio GJ, Van DongenMelman J, et al. Guidelines for assistance to terminally ill children with cancer: a report of the SIOP Working Committee on psychosocial issues in pediatric oncology. Med Pediatr Oncol 1999;32:44-8.

5. Nitschke R. Regarding guidelines for assistance to terminally ill children with cancer: report of the SIOP working committee on psychosocial issues in pediatric oncology. Med Pediatr Oncol 2000;34:271-3.

6. Nitschke R, Meyer WH, Sexauer CL, Parkhurst JB, Foster P, Huszti H. Care of terminally ill children with cancer. Med Pediatr Oncol 2000; 34:26870.

7. LevetownM, American Academy of Pediatrics Committee on Bioethics. Communicating with children and families: from everyday interactions to skill in conveying distressing information. Pediatrics 2008;121:e1441- 60.

8. Spinetta JJ, Jankovic M, Masera G, Ablin AR, Barr RD, Ben Arush MW, et al. Optimal care for the child with cancer: a summary statement from the SIOP Working Committee on Psychosocial Issues in Pediatric Oncology. Pediatr Blood Cancer 2009;52:904-7.

9. Himelstein BP, Hilden JM, Boldt AM, Weissman D. Pediatric palliative care. N Engl J Med 2004;350:1752-62.

10. Bluebond-Langner M. The Private Worlds of Dying Children. Princeton, NJ: Princeton University Press; 1978.

11. Hilden JM, Watterson J, Chrastek J. Tell the children. J Clin Oncol 2003; 21:37s-9s.

12. Mack JW, Joffe S. Communicating about prognosis: ethical responsibilities of pediatricians and parents. Pediatrics 2014;133(Suppl 1):S24-30.

13. Kreicbergs U, Valdimarsdottir U, Onelov E, Henter JI, Steineck G. Talking about death with children who have severe malignant disease. $\mathrm{N}$ Engl J Med 2004;351:1175-86.

14. Zelcer S, Cataudella D, Cairney AE, Bannister SL. Palliative care of children with brain tumors: a parental perspective. Arch Pediatr Adolesc Med 2010;164:225-30.

15. Beale EA, Baile WF, Aaron J. Silence is not golden: communicating with children dying from cancer. J Clin Oncol 2005;23:3629-31.

16. Sahler OJ, Frager G, Levetown M, Cohn FG, Lipson MA. Medical education about end-of-life care in the pediatric setting: principles, challenges, and opportunities. Pediatrics 2000;105:575-84.

17. van der Geest IM, Darlington AS, Streng IC, Michiels EM, Pieters R, van den Heuvel-Eibrink MM. Parents' experiences of pediatric palliative care and the impact on long-term parental grief. J Pain Symptom Manage

2014;47:1043-53. 
Geerst, I.M.M. van der, Heuvel-Eibrink, M.M. van den, Vliet, L.M. van, Pluijm, S.M.F., Streng, I.C., Michiels, E.M.C., Pieters, R., Darlington A.S.E. Talking about death with children with incurable cancer: perspectives from parents. Journal of Pediatrics: 2015, 167(6), 1320-1326

18. Ritchie J, Lewis J. Qualitative research practice: A guide for social science students and researchers. London: SAGE; 2003.

19. Gale NK, Heath G, Cameron E, Rashid S, Redwood S. Using the framework method for the analysis of qualitative data in multi-disciplinary health research. BMC Med Res Methodol 2013;13:117.

20. Marijs SE. To the Rainbow Forest. [Naar het Regenboogbos]. Soest:

Stuboek BV; 2007.

21. Wolfe L. Should parents speak with a dying child about impending death?

N Engl J Med 2004;351:1251-3.

22. Dunlop S. The dying child: should we tell the truth? Paediatr Nurs 2008; 20:28-31.

23. Schonfeld DJ. Talking with children about death. J Pediatr Health Care 1993;7:269-74.

24. Waechter EH. Children's awareness of fatal illness. Am J Nurs 1971;7: 1168-72.

25. Mack JW, Grier HE. The day one talk. J Clin Oncol 2004;22:563-6.

26. Young B, Dixon-Woods M, Windridge KC, Heney D. Managing communication with young people who have a potentially life threatening chronic illness: qualitative study of patients and parents. BMJ 2003;326:305. 27. Spinetta JJ. The dying child's awareness of death: a review. Psychol Bull 1974;81:256-60.

28. Spinetta JJ, Rigler D, Karon M. Anxiety in the dying child. Pediatrics 1973;52:841-5.

29. Carter BS, Levetown M, Friebert SE. Palliative Care for Infants, Children, and Adolescents: A Practical Handbook. Baltimore: The Johns Hopkins University Press; 2011.

30. Fredman G. Death talk, conversations with children and families. London: Karnac Books; 1997.

31. Kendrick C, Culling J, Oakhill T, Mott M. Children's understanding of their illness and its treatment within a pediatric oncology unit. Assoc Child Psychol Psychiat 1987;8:2-5.

32. Tanvetyanon T. Talking about death with dying children. N Engl J Med 2005;352:91-2. author reply 91-2.

33. Davies DE. Talking about death with dying children. N Engl J Med 2005; 352:91-2. author reply 91-2.

34. Korones DN. Talking to dying children: confessions from the trenches. AAHPM Bull 2004;5:1-3.

35. Wolfe J, Klar N, Grier HE, Duncan J, Salem-Schatz S, Emanuel EJ, et al. Understanding of prognosis among parents of children who died of cancer: impact on treatment goals and integration of palliative care. JAMA 2000;284:2469-75.

36. Worden JW. Grief counselling and grief therapy. A handbook for the mental health practitioner. London: Routledge; 2003.

37. Hinds PS, Drew D, Oakes LL, Fouladi M, Spunt SL, Church C, et al. Endoflife care preferences of pediatric patients with cancer. J Clin Oncol 2005;23:9146-54.

38. Hinds PS, Oakes L, Furman W, Foppiano P, Olson MS, Quargnenti A, et al. Decision making by parents and healthcare professionals when 
Geerst, I.M.M. van der, Heuvel-Eibrink, M.M. van den, Vliet, L.M. van, Pluijm, S.M.F., Streng, I.C., Michiels, E.M.C., Pieters, R., Darlington A.S.E. Talking about death with children with incurable cancer: perspectives from parents. Journal of Pediatrics: 2015, 167(6), 1320-1326

considering continued care for pediatric patients with cancer. Oncol Nurs Forum 1997;24:1523-8.

39. Hinds PS, Oakes LL, Hicks J, Powell B, Srivastava DK, Spunt SL, et al. "Trying to be a good parent" as defined by interviews with parents who made phase I, terminal care, and resuscitation decisions for their children. J Clin Oncol 2009;27:5979-85.

40. October TW, Fisher KR, Feudtner C, Hinds PS. The parent perspective: "being a good parent" when making critical decisions in the PICU. Pediatr Crit Care Med 2014;15:291-8. 
Geerst, I.M.M. van der, Heuvel-Eibrink, M.M. van den, Vliet, L.M. van, Pluijm, S.M.F., Streng, I.C., Michiels, E.M.C., Pieters, R., Darlington A.S.E. Talking about death with children with incurable cancer: perspectives from parents. Journal of Pediatrics: 2015, 167(6), 1320-1326

\section{TABLES AND FIGURES}

Table. Characteristics of the parents and children in this study

\begin{tabular}{lcc|}
\hline & Parents & Children \\
\hline $\mathrm{N}$ & 86 & 56 \\
Sex, N (\%) & & \\
$\quad$ Male & $32(37 \%)$ & $41(73 \%)$ \\
$\quad$ Female & $54(63 \%)$ & $15(27 \%)$ \\
$\begin{array}{l}\text { Median age at time of questionnaire, } \\
\quad \text { years (range) }\end{array}$ & $44(25-59)$ & NA \\
$\begin{array}{l}\text { Median age at death, years (range) } \\
\text { Diagnosis, N (\%) }\end{array}$ & NA & $7(1-17)$ \\
$\quad$ Hematological malignancy & NA & $21(37 \%)$ \\
$\quad$ Brain tumor & NA & $20(36 \%)$ \\
$\quad$ Solid tumor & NA & $15(27 \%)$ \\
\hline
\end{tabular}

Figure 1. Schematic overview of the reasons why the parents in this study chose not to discuss the topic of death with their child with terminal cancer. The 7 general themes are indicated, with specific reasons shown for each category.

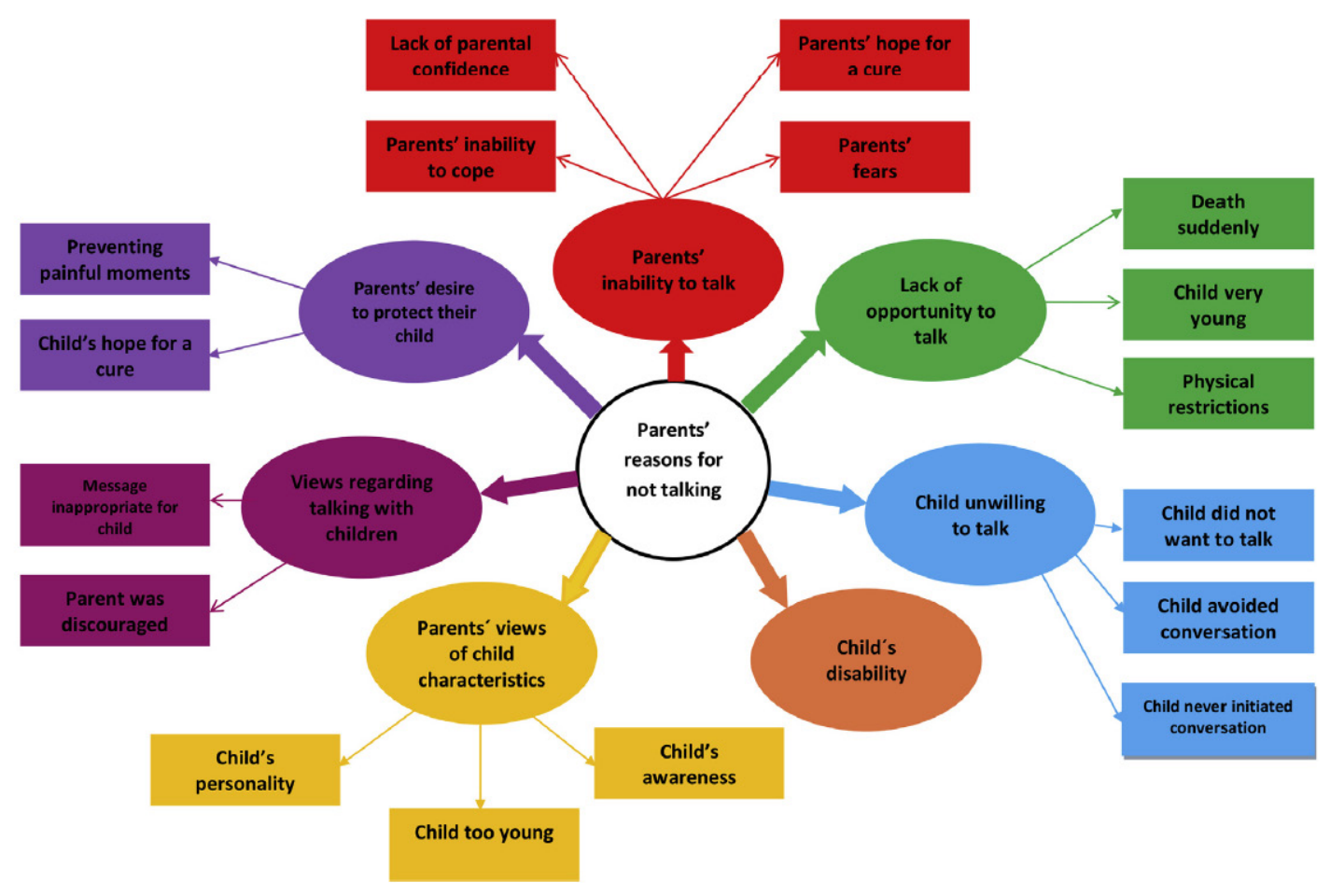


Geerst, I.M.M. van der, Heuvel-Eibrink, M.M. van den, Vliet, L.M. van, Pluijm, S.M.F., Streng, I.C., Michiels, E.M.C., Pieters, R., Darlington A.S.E. Talking about death with children with incurable cancer: perspectives from parents. Journal of Pediatrics: 2015, 167(6), 1320-1326

Figure 2. Summary of the parents' self-reflection regarding their decision to either discuss or not discuss death with their child. Left, 55 parents of 35 children did not discuss death with their child. When asked whether they felt positive about this decision, 29, 6, and 12 parents answered "yes," "no," and "I don't know," respectively (8 parents did not answer this question). Right, 31 parents of 21 children talked with their child about death. When asked whether they felt positive about this decision, 24,4 , and 2 parents answered "yes," "no," and "I don't know," respectively (1 parent did not answer this question).
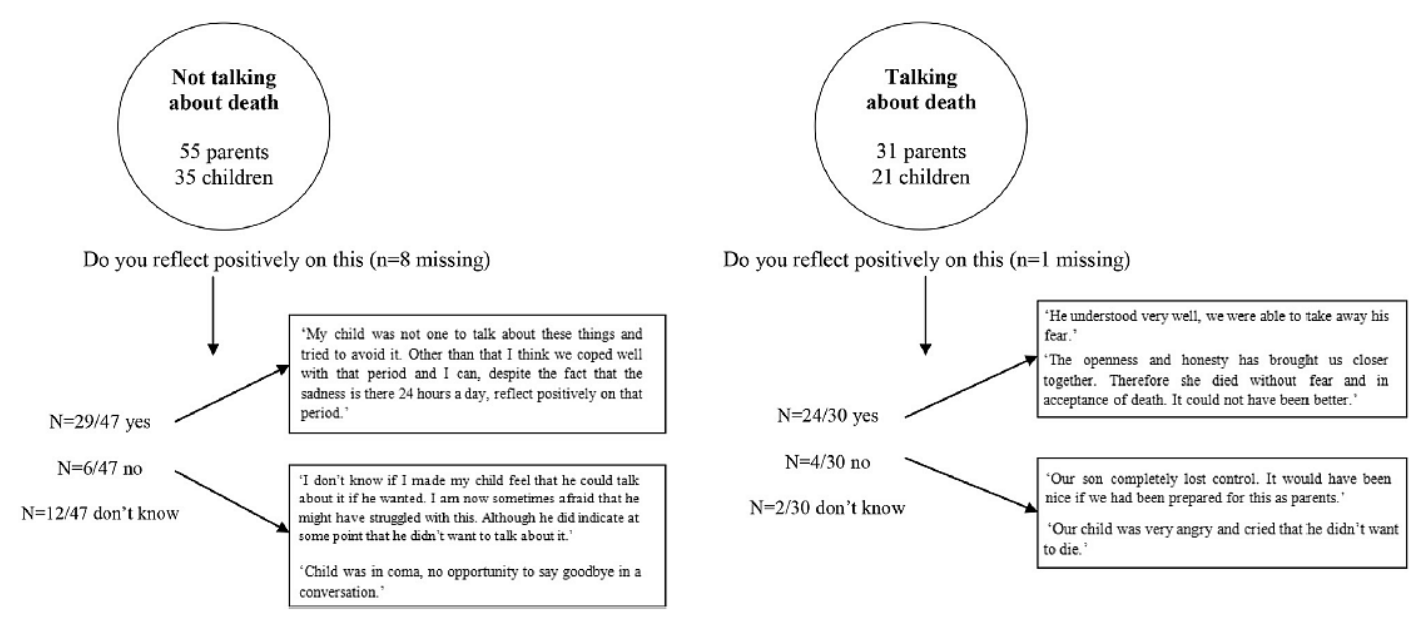